UNIVERSITY of NORTH FLORIDA.

\section{Journal of Counseling Sexology \& Sexual} Wellness: Research, Practice, and Education

\title{
LGBTQ* Responsive Sand Tray: Creative Arts and Counseling
}

\author{
Melissa Luke \\ Syracuse University \\ Harvey C. Peters \\ Syracuse University
}

Follow this and additional works at: https://digitalcommons.unf.edu/jcssw

Part of the Counseling Commons

\section{Recommended Citation}

Luke, M., \& Peters, H. C. (2019). LGBTQ* Responsive Sand Tray: Creative Arts and Counseling. Journal of Counseling Sexology \& Sexual Wellness: Research, Practice, and Education, 1 (1). https://doi.org/ 10.34296/01011002

This Article is brought to you for free and open access by the Brooks College of Health at UNF Digital Commons. It has been accepted for inclusion in Journal of Counseling Sexology \& Sexual Wellness: Research, Practice, and Education by an authorized administrator of UNF Digital Commons. For more information, please contact Digital Projects.

() 2019 All Rights Reserved

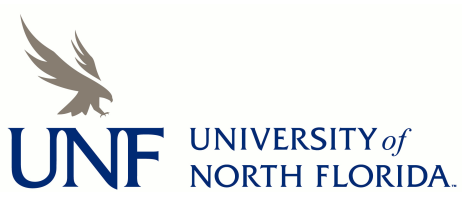




\section{LGBTQ* Responsive Sand Tray: Creative Arts and Counseling}

\section{Cover Page Footnote}

(1) Department of Counseling and Human Services, Syracuse University, 440 Sims Hall, Syracuse, NY 13244, USA. E-mail: mmluke@syr.edu 


\title{
LGBTQ* Responsive Sand Tray: Creative Arts and Counseling
}

\author{
Melissa Luke \\ Syracuse University
}

\author{
Harvey C. Peters \\ Syracuse University
}

\begin{abstract}
This article builds upon a heuristic framework for sand tray in supervision, multicultural focus areas, and the supervisory roles of teacher, consultant, and counselor to propose a framework for LGBTQ* responsive sand tray. This proposed framework provides supervisors with a creative arts-based structure to assist both counselors-in-training and practitioner supervisees in working with LGBTQ* persons, in a way that is culturally responsive and affirmative of their LGBTQ* identity. This article provides a group supervision case example and discussion to highlight the enactment and process of utilizing the proposed creative-arts framework.
\end{abstract}

Keywords: sand tray, supervision, counselor education, LGBTQ, creative-arts, creativity

\section{Introduction}

Scholars have argued that unlike purely talk-based therapies, tools, or interventions, creative arts have the potential to awaken new possibilities related to how individuals experience, examine, or engage in meaning making within a complex world and society (Gladding, 2010; Kapitan, Litell, \& Torres, 2011). Creative arts have been used with a variety of different populations (e.g., students, people of color, queer persons, adolescents), a multitude of issues and concerns (e.g, trauma, sexual identity and wellness, anxiety), and to address multicultural and social justice issues (Gladding, 2010; Paone, Malott, Gao, \& Kinda, 2015). Within the creative arts literature, there is a range of modalities, such as dance, art, poetry, music, humor, and sand tray (ST; Gladding, 2010). ST is an expressive therapeutic modality that examines both intra- and interpersonal issues using ST materials such as sand, water, a tray of some sort, and various inanimate figurines (Isom, Groves-Radomski, \& McConaha, 2015) as a form of expression (Pappas, 2015). Unlike the well-documented benefits of creative arts within the counseling literature, the conceptual and empirical scholarship within the counseling profession associated with ST is in a state of development (Gladding, 2010). This is particularly relevant when considering the use of ST with developing multicultural competence or with marginalized populations and communities, such as the Lesbian, Gay, Bisexual, Transgender, and Queer* (LGBTQ*) community. Given the multiple communities represented within the acronym LGBTQ*, an asterisk is intentionally used to indicate that the identities named are incomplete, intersectional, and fluid (Luke, Goodrich, \& Bond, 2015).

Despite the gap in the literature, creative arts, particularly ST, have been identified as a useful tool or intervention for professional counselors, counselor educators, and supervisors (Gladding, 2010; Mullen, Luke, \& Drewes, 2007; Paone et al., 2015; Perryman, Moss, \& Anderson, 2016). Fur- ther, ST has been identified as an underutilized framework for developing student or supervisees' multicultural competence (Paone et al., 2015), especially when working with marginalized populations. ST provides a creative modality to assist students or supervisees in exploring, communicating, and making meaning of their internalized struggles or less accessible information (e.g., preconscious, unconscious) using symbols and miniatures in the sand (Garza-Chaves, Timm, \& Oeffinger, 2018; Gladding, 2010; Paone et al., 2015). Thus, like other creative arts, ST has the potential to provide a framework for counselors to explore and expand their multicultural competence (Paone et al., 2015), while increasing their ability to support marginalized communities in exploring their own experiences, needs, and mental health with a modality that has been positioned as culturally responsive (Garza-Chaves et al., 2018; Paone et al., 2015). Therefore, this article will build upon the current counseling ST literature by adapting the use of ST to benefit a specific marginalized community, the LGBTQ* community, or more specifically, LGBTQ* persons with intersecting affectional orientations, genders, and sexual identities, given that the LGBTQ* acronym includes each of the intersecting identities (ALGBTIC LGBQQIA Competencies Taskforce et al., 2013; Cavanaugh \& Peters, 2019).

Developing the use of ST to serve the LGBTQ* com-

\begin{tabular}{|c|}
\hline Corresponding Author \\
\hline Melissa Luke \\
Syracuse University \\
440D Sims Hall \\
Syracuse, NY 13244 \\
E: mmluke@ syr.edu \\
P: (315)443-5265 \\
\hline
\end{tabular}


munity is crucial, as the LGBTQ* community faces many issues, such as discrimination, bullying, and homelessness (Goodrich \& Luke, 2015); internalized homophobia and genderism (Farmer \& Byrd, 2015); dating and sexuality (Cavanaugh \& Peters, 2019; Zeglin, Van Dam, \& Hergenrather, 2018); emotional, physical, and sexual abuse (Dank, Lachman, Zweig, \& Yahner, 2013); and a variety of mental health and substance-use-related issues (Cochran, Björkenstam, \& Mays, 2017; Thorne et al., 2018). More importantly, scholars have suggested that counselors and related mental health professionals are not adequately prepared to work with those within marginalized affectional orientations and gender identities or the many issues LGBTQ* persons face (Luke \& Goodrich, 2012, 2013), such as dating and sexuality (Cavanaugh \& Peters, 2019; Zeglin et al., 2018). As a result, this article builds upon the literature preparing counselors to provide effective, culturally responsive, ethi$\mathrm{cal}$, and just services to those with diverse affectional orientations, gender identities, and sexualities, through clinical supervision.

\section{Sand Tray: A Creative Approach}

As noted above, the purported utility of ST as a creative arts intervention has been established in the counseling literature (Bratton, Ceballos, \& Ferebee, 2009; Garrett, 2013, 2015b; Isom et al., 2015; Lyles \& Homeyer, 2014; Nickum \& Purgason, 2017; Paone et al., 2015), albeit, mostly conceptually. Despite the conceptual nature of ST within the counseling literature, multiple studies have empirically examined the process and benefits of ST within the counseling profession (Paone et al., 2015; Stark \& Frels, 2014; Swank \& Lenes, 2013). The use of ST has been documented across time and cultures, and has developed out of personal phenomenological hermeneutic research (De Domenico, 1988; Graham, Scholl, Smith-Adcock, \& Wittmann, 2014). Originally developed out of Lowenfeld's (1979) world technique and modified by Kalff (2004), ST has been purported to promote healing and growth, effectively respond to trauma, increase self-esteem, facilitate the counseling process and counteract resistance, and attend to culturally specific issues, such as gender and race (Chang, Ritter, \& Hays, 2005; Paone et al., 2015). Stark and Frels (2014) suggested that ST also offers opportunities as a collaborative assessment for counselor development, especially with counselors-in-training. As an expressive arts supervision activity, ST provides a shared symbolic language for supervisee and supervisor, and can assist in exploring case conceptualization and counseling dynamics (Chang et al., 2005; Stark, Garza, Bruhn, \& Ane, 2015), as well as increasing supervisee self-awareness and expression (Carnes-Holt, Meany-Walen, \& Felton, 2014; Garrett, 2015a; McCurdy \& Owen, 2008).

Over the past decade, the counseling research has begun to examine the utility and effectiveness of ST in counsel- ing and supervision (Anekstein, Hoskins, Astramovich, Garner, \& Terry, 2014; Garza-Chaves et al., 2018; McCurdy \& Owen, 2008). While ST has been implicated in its ability to tap into both conscious and unconscious creative processes (Anekstein et al., 2014; Paone et al., 2015), research has supported the ways in which ST utilizes visual, kinesthetic, and expressive communication (Stark et al., 2015), arguably all aspects of creative expression. Supervisees have described their experiences with ST in supervision as positive (Markos, Coker, \& Jones, 2008; McCurdy \& Owen, 2008) and for these reasons, Goodrich and Luke (Goodrich \& Luke, 2015) identified the particular utility of expressive, experiential, and creative approaches in supervision of counselors working with LGBTQ* clients. Because ST can be utilized within a variety of theoretical approaches, such as Person Centered, Jungian, Adlerian, Gestalt, Developmental, and Psychodynamic (Isom et al., 2015; McCurdy \& Owen, 2008; Perryman et al., 2016), supervisors have a range of ways in which they can incorporate ST into extant supervision models (Anekstein et al., 2014; Carnes-Holt et al., 2014; Stark, Frels, \& Garza, 2011). For example, Garrett (2015b) described use of journaling as an extension of the ST experience in supervision, while others incorporate photography, painting and drawing, or titling, as well as various forms of narrative and reflective practices (Luke, 2008; Mullen et al., 2007). Although the literature does not suggest an ideal theoretical lens or creative approach, Perryman et al. (2016) indicated that the selection of a theoretical lens should be based on several factors, such as one's training, supervisee or supervisor development level, context, population, and supervisory relationship. Thus, supervisors and counselor educators should consider such factors when selecting an appropriate and ethical framework for ST within supervision.

\section{Incorporating Sand Tray into Supervision of Counselors Working with LGBTQ* Clients}

Within counseling and other related mental health professions, clinical supervision has long been recognized as the primary modality for intrapersonal and interpersonal skill development (Bernard \& Goodyear, 2013; Bernard \& Luke, 2015). Such professional development supports the expansion of counselors' attitudes, beliefs, knowledge, skills, and actions when working with diverse populations across different professional settings and contexts (Ratts, Singh, NassarMcMillan, Butler, \& McCullough, 2016). As a result, multiple approaches have been developed and utilized as a means of supporting counselors' multicultural and social justice development within supervision (Bernard \& Goodyear, 2013; Bernard \& Luke, 2015). One such area includes creative arts and more specifically, ST (Anekstein et al., 2014; Bernard \& Goodyear, 2013; Carnes-Holt et al., 2014; Stark et al., 2011).

As mentioned above, creative arts have been used to promote a wide variety of professional skills, behaviors, 
and abilities, such as expressive and reflective processes (Gladding, 2010), increased self-other awareness (Bratton, Ceballos, \& Sheely, 2008), and increased access to intuition, empathy, and emotion (Carnes-Holt et al., 2014). In supervision, Stark et al. (2014) suggested that as a specific creative arts intervention, ST could uniquely assist supervisees to conceptualize, establish counseling and supervisory goals, and enhance the counseling and supervisory relationships. Furthermore, ST has recently been extended into multicultural counseling training contexts as well. In a qualitative study with 43 counselors-in-training, Paone et al. (2015) found that counselors-in-training reported that ST facilitated their expression and new learning in supervision as well as being a positive and meaningful group experience. The authors further argued this study provided initial support for the use of ST as an intervention aimed at assisting students or supervisees in expressing difficult emotional or sensorimotor feelings and experiences, thereby allowing them to become more cognizant, insightful, and emotionally attuned to their feelings and biases that could have otherwise impeded their multicultural competence or abilities as counselors.

Other research supports the use of ST in group contexts (Bratton et al., 2009; Kestly, 2010; Swank \& Lenes, 2013), with researchers theorizing that the group context reduces isolation and promotes a sense of universality (Yalom \& Leszcz, 2005), specifically related to multicultural counseling training difficulties (Paone et al., 2015). That said, there has been limited discussion about how ST can be employed in group supervision (Luke, 2008) and virtually no literature that specifically focuses on the utility of ST with supervisees who are working with LGBTQ* clients. For the purposes of this manuscript, "supervisees" refers to counselorsin-training, counselors accruing hours towards licensure, and licensed practitioners receiving supervision.

Goodrich and Luke (2015) stated that while the counseling and supervision literatures have increasingly responded to the needs of LGBTQ* persons, clients who identify LGBTQ* continue to frequently report negative counseling experiences that do not reflect recognized standards, best practices, or counselor multicultural competence (Buser, Goodrich, Luke, \& Buser, 2011; Goodrich, Buser, Luke, \& Buser, 2015). Therefore, Luke and Goodrich (2015a, 2015b) purported that supervision offered a direct mechanism to increase counselors' multicultural competence, social justice competence, and clinical competence when working with LGBTQ* individuals. Increasing counselors' ability to serve LGBTQ* persons is of the utmost importance, given that persons who identify as LGBTQ* seek counseling services at disproportionately higher rates than their heterosexual and gender normative peers (Cochran et al., 2017; Dilley, Simmons, Boysun, Pizacani, \& Stark, 2010; FredriksenGoldsen et al., 2014; Luke \& Goodrich, 2015a; Thorne et al., 2018). One such study conducted by Grella, Green- well, Mays, and Cochran (2009) reported that LGBTQ* persons experiencing mental health-related issues sought mental health or substance-use services within the last year at a rate of $48.5 \%$, while their counterparts sought the same services at a rate of $22.5 \%$. Further, several authors have argued that the multiple forms of discrimination experienced by LGBTQ* persons are linked to increased mental health issues, which can begin to explain LGBTQ* personsâĂŹ disproportionate need for mental health services (Cochran et al., 2017; Thorne et al., 2018).

Given the high rates of discrimination and mental health concerns of LGBTQ* persons (Cochran et al., 2017; Thorne et al., 2018), it is concerning that counselor education has continued to overlook supervision as a means to increase LGBTQ* related multicultural competence and has instead primarily relied upon didactic training methods in isolated content courses of short duration to educate counselors on the needs of clients who may identify as LGBTQ* (Jennings, 2014; Luke, Goodrich, \& Scarborough, 2011). As such , this article builds upon the use of ST in supervision (Anekstein et al., 2014; Markos et al., 2008; Paone et al., 2015; Stark et al., 2011), as ST offers a critical opportunity to redress the gaps in counselor education (Stark \& Frels, 2014). Creative arts interventions in general, and ST in particular, have been lauded as offering supervisors a complementary right-brain and kinesthetic means (Stark \& Frels, 2014) to creatively and experientially work with supervisees to match their developmental needs (Mullen et al., 2007). As a creative and experiential intervention, ST offers supervisors opportunities to select learning activities that differentially respond to varied developmental needs of the supervisee (Anekstein et al., 2014; Carnes-Holt et al., 2014; Paone et al., 2015) working with clients across the LGBTQ* communities (Goodrich \& Luke, 2015).

While supervision has long been recognized as the signature pedagogy for training counselors broadly (Bernard \& Goodyear, 2013), more recently supervision has been acknowledged as an effective means to develop counselor LGBTQ* competence and ally development specifically (Luke \& Goodrich, 2015a; Moe, Perera-Diltz, \& Sepulveda, 2014). Interestingly, over the past decade there has been more focus on the needs of LGBTQ* clients in the counselor education literature and increased incorporation of creative art approaches (Bernard \& Luke, 2015; Inman \& Kreider, 2013; Soheilian, Inman, Klinger, Isenberg, \& Kulp, 2014), but there is minimal extant literature that combines the two.

In the section that follows, the model for LGBTQ* responsive supervision (Goodrich \& Luke, 2011; Luke \& Goodrich, 2012, 2013, 2015a, 2015b, 2017) and the creative arts framework identified by Stark and Frels (2014) are synthesized to illustrate how ST can be used in the supervision of counselors working with LGBTQ* clients. Similar to how Guiffrida (2015) described constructivist approaches 
to supervision as offering a means for supervisor and supervisee to co-construct the supervisory processes and meanings, what follows includes a description of the types of materials needed for ST in supervision (Garrett, 2013) and how the supervisor can broach supervisees to engage in this creative approach related to their work with LGBTQ* clients (Goodrich \& Luke, 2015; Luke \& Goodrich, 2015a). This model will be followed by a description of how supervisors can co-construct the use of ST as a creative and expressive supervisory intervention (Carnes-Holt et al., 2014; Graham et al., 2014) to demonstrate ways in which the supervisee might use ST with LGBTQ* clients (Anekstein et al., 2014; Markos et al., 2008; Paone et al., 2015). Finally, there will be a discussion of how supervisors can facilitate supervisees' transfer of the creative and experiential learning into their clinical practices, including post-supervisory extensions (Guiffrida, 2015) that hold particular salience for counselors working with clients who identify as LGBTQ* (Goodrich \& Luke, 2015).

\section{LGBTQ* Responsive Sand Tray}

To address earlier identified purposes, the LGBTQ* Responsive Sand Tray approach in supervision is proposed as a means to assist supervisors and counselor educators in creatively and experientially supporting counselors' work with LGBTQ* clients with differing affectional, gender, and sexual identities. As such, the LGBTQ* Responsive Sand Tray approach integrates transtheoretical LGBTQ* responsive supervision models (Goodrich \& Luke, 2009; Luke \& Goodrich, 2012, 2013, 2015a, 2015b, 2017) and the four stages of ST work identified by Stark and Frels (2014). Each framework provides a transtheoretical, concrete, pragmatic, and flexible approach; thus, they are theoretically compatible.

The transtheoretical LGBTQ* responsive supervision models developed by Luke and Goodrich were constructed through the integration of multiple theories, models, and frameworks (Goodrich \& Luke, 2011; Luke \& Goodrich, 2013; Miller \& Luke, 2018), such as Group Systems Theory (Agazarian, 1997, 2001), the Discrimination Model (Bernard, 1979, 1997; Rubel \& Okech, 2006), and multicultural frameworks and competencies (Atieno Okech \& Rubel, 2007; Sue, Arredondo, \& McDavis, 1992). As a result, the transtheoretical LGBTQ* responsive supervision models included points of entry for individuals and groups (i.e., intrapersonal, interpersonal, group-as-whole, supra-group), multicultural and LGBTQ* foci (i.e., knowledge, awareness, skills), and the supervisory role (i.e., teacher, counselor, consultant; Goodrich \& Luke, 2011; Luke \& Goodrich, 2013; Miller \& Luke, 2018). The points of entry, multicultural and LGBTQ* foci, and supervisory roles were identified as an ideal systematic framework to assist individuals and groups in their ability to better serve the needs of LGBTQ* per- sons, as there was a gap in the supervision literature (Luke \& Goodrich, 2013; Miller \& Luke, 2018).

For instance, depending on the supervisory or educational context and the needs of students, supervisees, and/or clients, this framework provides a concrete structure to support supervisors and counselor educators in ensuring their students or supervisees can adequately meet the needs of LGBTQ* persons (Goodrich \& Luke, 2011; Luke \& Goodrich, 2013; Miller \& Luke, 2018), whether by addressing their biases, lack of LGBTQ* knowledge or skills, countertransference, or various points of entry. Such issues or growth edges can cover a plethora of issues, such as preconceived notions of LGBTQ* dating, sexual relationships and intimacy, or norms; the intersections of gender identity, affectional orientation, and spiritual and religious identity; or the oppressive, homophobic, sexist, transphobic, and hegemonic experiences that impact LGBTQ* persons' overall wellness, mental health, and safety (Cavanaugh \& Peters, 2019; Farmer \& Byrd, 2015; Goodrich \& Luke, 2015; Thorne et al., 2018).

Accordingly, the transtheoretical LGBTQ* responsive supervision models (Goodrich \& Luke, 2009, 2011; Luke \& Goodrich, 2012, 2013, 2015a, 2015b, 2017) and the four stages of ST work identified by Stark and Frels (2014) have been combined to expand the ST and supervision literature aimed at fostering LGBTQ* competence, as they are purported to be pragmatic and flexible models. Additionally, given that the models developed by Goodrich and Luke (2011) and Luke and Goodrich (2012, 2013, 2015a, 2015b, 2017) were focused on expanding counselors' abilities to serve LGBTQ* persons as well as the various concerns presented by LGBTQ* persons, these models provided an LGBTQ* centered framework. Unlike other LGBTQ* oriented supervision frameworks or models, such as the Integrative Affirmative Supervision Model (Halpert, Reinhardt, \& Toohey, 2007) or the Queer People of Color Resilience-Based Model of Supervision (Chun \& Singh, 2010), Goodrich and Luke (2011) and Luke and Goodrich (2012, 2013, 2015a, 2015b, 2017) models were developed for individual and group supervision; allot for various intersecting affectional orientations, gender identities, and sexualities; have been examined empirically; are pragmatic in nature; and can be used across different counseling and supervision theories (Luke \& Goodrich, 2013; Miller \& Luke, 2018). Thus, they arguably provide an ideal platform for LGBTQ* Responsive Sand Tray.

As a result, the authors purport that the LGBTQ* Responsive Sand Tray approach in supervision can provide supervisors with a temporal, creative arts process to better meet the needs of counselors working with LGBTQ* clients. Although the LGBTQ* Responsive Sand Tray approach is flexible enough to use in both individual or group supervision, the group context offers unique and additive benefits, such as developing a space in which group members are encour- 
aged to be empathic; share their lived experiences, insights, and knowledge; promote interpersonal learning; and provide and receive feedback from fellow group members (Goodrich \& Luke, 2015; Swank \& Lenes, 2013). It is expected that through the creative and experiential approach, counselors will have sensitivity to the needs of their LGBTQ* clients, greater awareness of ways in which their own worldview impacts their counseling, and more developed skills to provide culturally competent services.

\section{Phases}

The first step in using the LGBTQ* Responsive Sand Tray approach in supervision involves what Stark and Frels (2014) identified as temporal phases of the ST process. In the initial introduction phase, the supervisor discusses the purposes and process of ST work and invites the supervisee to consider their interest and motivation for use. In this phase, the supervisor shares some composite case examples of the ways in which ST work can take place and how and why the supervisor believes that it will be useful with the supervisee in their work with LGBTQ* clients in particular. The supervisor may wish to facilitate the supervisee's exploration of the ST materials before ascertaining whether or not the supervisee is ready to proceed. Stark and Frels (2014) label the second step as the building phase, where the supervisor provides free range for the supervisee to reflect upon their work with the LGBTQ* client and represent an aspect in the sand tray. During this phase, the supervisor observes and accompanies the supervisee in exploring and selecting from the miniatures. The purpose of this phase is for the supervisee to construct their sand tray; in doing so, the supervisee is experientially and creatively representing aspects of their counseling with the LGBTQ* client.

Next, in the experiencing phase, the supervisee is reflecting upon and making meaning of their sand tray. During this phase, the supervisee may develop increased awareness, insight, and an interpretation of themselves, their client, the counseling relationship, or the supervisory experience. In the final connecting phase, the supervisee can transfer the knowledge across the earlier phases to their future work with the LGBTQ* client. Just as counselors may support clients in applying awareness, knowledge, or skills developed in counseling to other aspects of their functioning, so too can supervisors support counselors in applying the same to future work.

\section{Focus}

Across any of the phases of ST work, the supervisor must decide on the area of supervisee multicultural competence on which to focus, awareness, knowledge, or skills (Sue et al., 1992). Although a supervisor can likely begin with any one area of focus and sequentially move to another, others have suggested that supervisees benefit from clarity and transparency about the specific focus at any given time. Said another way, Bernard (1997) cautioned the supervisor about sliding across focus areas, starting to address one focus and without explicitly noting, shifting to another focus. Bernard suggested that this is unnecessarily confusing to the supervisee. Thus, it is recommended that the supervisor intentionally and transparently shift focus areas in response to the supervisee's perceived needs in a sequential manner (Luke \& Bernard, 2006).

\section{Roles}

The final step in navigating the LGBTQ* Responsive Sand Tray approach in supervision involves the supervisor deciding on the role from which the supervisory intervention will be delivered, from the teacher, counselor, or consultant roles (Bernard, 1979). Luke and Bernard (2006) noted that supervisors may have a theoretical or stylistic preference for specific roles, and supervisees may similarly have a preferred role through which they receive feedback or instruction (Bernard \& Goodyear, 2013). That said, research has indicated that supervisor flexibility in intervening across supervisory roles is associated with better supervision outcomes (Falender \& Shafranske, 2004; Ladany, Marotta, \& Muse-Burke, 2001) and that supervisor role can influence subsequent supervisee focus (Stenack \& Dye, 1982).

\section{Case Example}

Leah is a master's student and intern at a community counseling agency in a city just 20 minutes from where she lives. She is in her last semester of her studies as a clinic mental health counselor and currently enrolled in an internship course where she has the opportunity to present her cases, videos of her counseling sessions, seek additional supervision, and consult with her peers and professor. Leah is a 26year-old Caucasian individual who identifies as cisgender, female, monosexual, and Lesbian. Leah has been "out of the closet" since she was 16 years old and feels quite connected to the LGBTQ* community. Leah grew up in a community and household that was LGBTQ* affirming, sex-positive, agonistic, and encouraged individual identity exploration.

Leah has recently been given a few additional clients because she is hoping to build her caseload in hopes of finishing her program hours. Through this process, she has recently started seeing an 18-year-old LatinX individual who identifies as a cisgender male and is beginning to identify himself as a guy who likes guys. Leah's client also belongs to a community and household that is less affirming of the LGBTQ* community, Catholic, and values the concept familismo. In her internship course, Leah recently presented a tape and her body of work with this client whom she had seen for a total of four sessions. Leah identified her theoretical orientation, case conceptualization, and identified how she would like assistance from the professor and class. Leah stated that 
she feels well connected to this client and that she has observed many similarities between their lived experiences, as she stated, "I remember being in the same situation and experiencing the exact same things at his age." Because of her felt similarities, Leah reported disclosing during her second session with her client that she identifies as Lesbian.

Since the disclosing of her affectional orientation, the client has begun to ask many questions about her lived experiences as a Lesbian woman, her journey exploring samegender sexual and intimate relationships, and how her family and community handled her affectional orientation. As a result, Leah has felt some dissonance because she has wanted to use more self-disclosure in session; however, she now realizes that her disclosure might not have been in the best interest of the client, nor is it the correct use of her conceptualization of self-disclosure. Although Leah did not believe that his request was unreasonable or harmful, she experienced some internal hesitance, but was not certain as to why she was experiencing hesitance. Nonetheless, Leah shared her struggle of whether to share more or keep reflecting the client's desire to have a piece of her, the counseling session, and the experience of another LGBTQ* individual.

Leah presented this information, a 20-minute segment of her work with this client, and there was some time for group supervision discussion. Within the internship course, there are six students, a doctoral-level teaching assistant, and a professor. Her internship professor Dr. Bloom identifies as a 58-year-old Black heterosexual woman. Dr. Bloom has acknowledged some of the intrapersonal struggles that Leah has identified during class and has invited Leah to partake in the use of ST as a supervisory intervention, while the class observes the process with the teaching assistant. Thus, Dr. Bloom decided to begin with an intrapersonal point of entry.

Dr. Bloom explains the utility and process of ST, the ST framework, and past student/supervisee experiences, while providing Leah with some time to reflect on her work with this client. Afterwards, Dr. Bloom invites Leah to create a ST focused on her dissonance with sharing her experiences and narrative as Lesbian woman with her client. After having some time to reflect, Dr. Bloom provides Leah with some space to select miniatures that represent her dissonance related to sharing more about her LGBTQ* experiences with the client who identifies as a guy who likes guys. Leah begins to select miniatures and slowly places them within the sand tray as Dr. Bloom observes and accompanies Leah in the process. Leah draws a Venn diagram in the sand and dedicates one circle to her client's experiences and narratives, one for herself, and one for what she believes they share.

Leah takes much time in her selections of the miniatures as well as her placement of them within the sand. As Leah continues to select and place miniatures, Dr. Bloom verbalizes her observations of her student. During this process, Leah attempts to make meaning and reflect on her experience and process of using the ST as a representation of her with her client. Dr. Bloom sits with Leah but does not critique, analyze, or provide her supervisee with solutions. Instead, Dr. Bloom is assisting Leah in her process of creating a tray that engenders her own self-reflection and meaning making.

Leah slowly begins to become more intense in her interactions with the ST and with her professor. After a few more minutes pass, Leah releases a deep sigh and reports to Dr. Bloom that she believes she is finished and no longer feels torn; she knows what she feels now. Leah further discloses that she did not have the same experience as her client, and even though she wanted him to have a similar support system as she once had, she recognizes that their support systems and lived experiences are different. Dr. Bloom and Leah related this experience, and new insight towards future movement with the client.

For instance, given that Dr. Bloom was cognizant of Leah's current state of LGBTQ* awareness, knowledge, and skills, she decided to use the role of counselor to process Leah's missed awareness regarding how she and her client differ in many ways, such as faith, family-community relationships and values, affectional identity, gender identity, and racial identity. Dr. Bloom also opened up the ST to the rest of the group, and one student reflected that Leah reported through her Venn diagram circles and figures that she was in a relationship and sexually active at 17 years old, while her client reported liking men, but was uncertain of his comfortability engaging in anything beyond kissing and holding hands with another man. Dr. Bloom also facilitated other interpersonal and group-as-whole interactions with Leah and the ST. These interactions assisted Leah and Dr. Bloom in further exploring how Leah can use this experience to intentionally provide more culturally responsive, socially just, and effective services to this client and other future LGBTQ* clients and issues (Luke \& Goodrich, 2015a, 2015b).

\section{Discussion}

As noted in the case example, Dr. Bloom acknowledged and reflected on some of Leah's intrapersonal struggles she observed in Leah's class presentation and tape of her clinical work. As a result, Dr. Bloom intentionally began the first step (Stark \& Frels, 2014) of the LGBTQ* Responsive Sand Tray by inviting Leah to partake in ST, in order to explore her conceptualizations and personalizations that were influencing her clinical work with her client. Dr. Bloom shared her rationale, framework, and invited Leah to participate in the ST. Dr. Bloom also socialized Leah into the ST modality and normalized some potential reactions and/or types of experiences. Other questions and prompts that could be used within this step include the following:

- It is not unusual for supervisees to have mixed reactions to their initial use of ST. What is happening for you (Leah)? What is happening for you (class)? 
- I'm noticing that you seem more uncertain than is typical. Do you want to talk about what's happening for you?

- Sometimes supervisees want more/less information about what is expected or what might happen with the ST. How will we decide what's the right amount for our supervision work together? How will you (class) negotiate this for yourselves?

Dr. Bloom enacted the second step (Stark \& Frels, 2014), as she provided Leah with free range to reflect upon her work and experience with her LGBTQ* student. Although some supervisors prefer a directive approach (Garrett, 2015b, 2016) that includes analysis, notice that Dr. Bloom did not provide Leah with any interpretations or critiques here, just her observations of Leah and what was occurring. Other process observations or prompts that could be used within the second step include the following:

- Tracking type statements like, I'm noticing that you are placing $\mathrm{X}$ over there, and that you keep moving Y.

- What might you add that I haven't addressed yet (to the class)?

- Reflection-type statements like, It looks like you're concentrating/are feeling inhibited/are experiencing something right now. Would you like to discuss this?

- Hmm, I wonder what these objects might say to each other.

- I'm noticing that $X$ is being brought up for me right now. I can't help thinking that your client/peers might have a reaction to this ST too.

The third step (Stark \& Frels, 2014) was enacted by Dr. Bloom, as she assisted Leah in developing further selfawareness, insight, and interpretation as to Leah, her client, multicultural and LGBTQ* foci, and their therapeutic relationship. During this process, Leah is able to begin to separate her own experiences from her client's experiences as a guy who likes guys, which provided Leah with a sense of relief. Other questions and prompts that could be used within this step include the following:

- Now that we have discussed this a little, what else might you wish to add to/take away from the ST?

- Sometimes it can be helpful to journal about X, or to develop a dialogue between $\mathrm{X}$ and $\mathrm{Y}$. What are your initial reactions to these ideas?

- Considering the $\mathrm{X}$ foci, how do you make meaning of the similarities and differences between your client's LGBTQ* experiences and your own?
- If you were to give this ST a title, what might it be? Is there a fitting subtitle, or chapter names (Leah or the class)?

Following this, Dr. Bloom demonstrated the fourth step (Stark \& Frels, 2014) where she began to further connect Leah's meaning making and insights into her future work with LGBTQ* clients; thus, the transferring of knowledge and process into action piece began. This step is attending to Leah's growth and development as a counselor. Other questions and prompts that could be used within this step to promote application or consolidation include the following:

- As you envision your future work with this client, what might a future ST contain?

- How will you address your client's affectional orientation and sexuality concerns in your upcoming sessions? What resources might you need for this work or areas for ongoing consultation (Leah or class)?

- How might our supervisory relationship be represented in this ST (or others) as you continue to expand your multicultural competence with LGBTQ* clients?

- What objects from this ST do you hope to see represented in your next session with this client? In our future supervision? In your ongoing work with other LGBTQ* clients? What do you want to leave right here (Leah or the class)?

When looking at the focus (i.e., awareness, knowledge, skills; Sue et al., 1992), Dr. Bloom could have focused on several areas, but due to Leah's reported intrapersonal struggles presented in class, Dr. Bloom attended to the awareness component. However, during the fourth step, she assisted Leah in moving beyond awareness, as she applied the awareness to knowledge and skills that could be cultivated in future sessions with LGBTQ* persons. Another important area within the case example was Dr. Bloom's intentional selection of a role (i.e., teacher, counselor, consultant; Bernard, 1979, 1997). Given the focus and needs of Leah, Dr. Bloom began by using the role of counselor. This was demonstrated by her use of self, skills, and use of attending to Leah's development. After she completed her work within this role, she transitions to the consultant role, as Leah and Dr. Bloom explore future directions, skills, and actions. Carnes-Holt et al. (2014) offered examples of ST supervisory interventions that can be used across the roles and foci within the Discrimination Model (Bernard, 1979, 1997).

\section{Implications}

Clients who identify as LGBTQ* experience higher rates of suicide, homelessness, bullying, educational obstacles, physical harm, and substance use than their heterosexual and 
gender normative peers (Cavanaugh \& Peters, 2019; Dank et al., 2013; Dilley et al., 2010; Fredriksen-Goldsen et al., 2014; Goodrich \& Luke, 2015). These experiences and historical issues regarding mental health services for LGBTQ* individuals situate the importance for services, training, supervision, and ethical guidelines when working with the LGBTQ* population (ALGBTIC LGBQQIA Competencies Taskforce et al., 2013; Luke \& Goodrich, 2015a; Moe et al., 2014; Troutman \& Packer-Williams, 2014). Documented within the counseling literature is the need and ethical responsibility for supervisors to foster supervisees' competence and ability to work and advocate for LGBTQ* clients (ALGBTIC LGBQQIA Competencies Taskforce et al., 2013; Goodrich \& Luke, 2015; Loue \& Parkinson, 2015; Moe et al., 2014; Troutman \& Packer-Williams, 2014). In addition, counselor educators and supervisors utilizing ST must recognize that ST is a form of creative arts (Gladding, 2010), ergo, similar to the use of any supervisory intervention or framework, counselor educators and supervisors need to understand the limitations and ethics behind utilizing ST in supervision (Bernard \& Goodyear, 2013; Stark \& Frels, 2014).

Thus, despite its diverse benefits, this modality should be used with caution (Loue \& Parkinson, 2015). Owing to the deeper reflective process (Stark \& Frels, 2014), ST can often blur the boundaries of supervision and counseling; it may go too deep too fast, and can cause harm by misinterpreting the art and themes (Anekstein et al., 2014; Isom et al., 2015; Stark \& Frels, 2014). Moreover, it is crucial that supervisors have appropriate training and experience with ST, understand that the limits of confidentiality apply to produced artwork, and supervise the use of ST by supervisees (Carnes-Holt et al., 2014; Garrett, 2013; Stark \& Frels, 2014; Stark et al., 2015). While researchers have indicated the benefits of ST (Markos et al., 2008; McCurdy \& Owen, 2008), further research on ST in supervision is needed to understand the effectiveness and utility of ST as a creative arts intervention. As most research on ST to date is qualitative, and descriptive in nature, there is a need to begin examining ST processes and outcomes using quantitative measures as well. Further, this work would benefit from examining the efficacy of ST in fostering LGBTQ* competence for supervisees (Anekstein et al., 2014; Goodrich \& Luke, 2015; Luke \& Goodrich, 2015a; Paone et al., 2015).

Additionally, future scholarly writing and research can build upon this proposed framework to further address the dearth of creative arts and ST literature focused on developing counselors who are prepared to provide culturally responsive services to persons with diverse affectional orientations, gender identities, and sexualities, especially the intersections of such identities across the lifespan. This is of the utmost importance, as LGBTQ* persons have unique experiences, needs, resiliencies, and mental health and wellness concerns, due to the intersections of these three specific identities (Cavanaugh \& Peters, 2019; Goodrich \& Luke, 2015). Furthermore, given the lack of counseling supervision literature and programmatic standards focused on these intersections, counselor educators and supervisors can use the LGBTQ* Responsive Sand Tray framework to proactively explore and address the intersections of affectional orientation, gender identity, and sexuality in clinical practice as well as courses, such as supervision, practicum and internship, human sexuality, multicultural and social justice, or group work (Cavanaugh \& Peters, 2019; Goodrich \& Luke, 2015; Zeglin et al., 2018).

\section{Conclusion}

The use of ST in supervision has various reported benefits for supervisees, such as processing difficult lived experiences and emotions around multiculturalism, cultivating personhood, developing awareness and reflexivity, and increasing empathy and understanding for clients' experiences (Anekstein et al., 2014; Carnes-Holt et al., 2014; Garrett, 2013, 2015b, 2015a, 2016; Paone et al., 2015). The incorporation of ST within supervision provides a place for professional and multicultural development, as well as a space for transformative discovery, processing, and insight into the inner thoughts and feelings of supervisees (Paone et al., 2015; Stark et al., 2015). ST transcends the identified roles of supervisor, supervisee, and client, as it has been purported as a deep and meaningful approach for various populations and clinical settings (Anekstein et al., 2014; Graham et al., 2014; Isom et al., 2015; Stark \& Frels, 2014). Thus, this framework and creative modality has much purported utility for the LGBTQ* community, particularly when preparing counselors and supervisees to explore and address the intersections of affectional orientation, gender identity, and sexuality within their clinical work.

\section{References}

Agazarian, Y. M. (1997). Systems-centered therapy for groups. The Guilford Press.

Agazarian, Y. M. (2001). A systems-centered approach to inpatient group psychotherapy. Jessica Kingsley Publishers.

ALGBTIC LGBQQIA Competencies Taskforce, Harper, A., Finnerty, P., Martinez, M., Brace, A., Crethar, H. C., ... Hammer, T. R. (2013). Association for lesbian, gay, bisexual, and transgender issues in counseling competencies for counseling with lesbian, gay, bisexual, queer, questioning, intersex, and ally individuals. Journal of LGBT Issues in Counseling, 7(1), 2-43. doi:10.1080/15538605.2013.755444

Anekstein, A. M., Hoskins, W. J., Astramovich, R. L., Garner, D., \& Terry, J. (2014). 'sandtray supervision': Integrating supervision models and sandtray therapy. 
Journal of Creativity in Mental Health, 9(1), 122-134. doi:10.1080/15401383.2014.876885

Atieno Okech, J. E., \& Rubel, D. (2007). Diversity competent group work supervision: An application of the supervision of group work model (SGW). The Journal for Specialists in Group Work, 32(3), 245-266. doi:10.1080/01933920701431651

Bernard, J. M. (1979). Supervisor training: A discrimination model. Counselor Education and Supervision, 19(1), 60-68. doi:10.1002/j.1556-6978.1979.tb00906.x

Bernard, J. M. (1997). The discrimination model. In C. E. Watkins (Ed.), Handbook of psychotherapy supervision (p. 310-327). Wiley.

Bernard, J. M., \& Goodyear, R. K. (2013). Fundamentals of clinical supervision (5th ed.). Pearson.

Bernard, J. M., \& Luke, M. (2015). A content analysis of 10 years of clinical supervision articles in counseling. Counselor Education and Supervision, 54(4), 242-257. doi:10.1002/ceas.12024

Bratton, S., Ceballos, P., \& Sheely, A. (2008). Expressive arts in a humanistic approach to play therapy supervision: Facilitating therapist self-awareness. In A. A. Drewes \& J. Mullen (Eds.), Supervision can be playful: Techniques for child and play therapist supervisors (p. 310-327). Rowman and Littlefield.

Bratton, S., Ceballos, P. L., \& Ferebee, K. W. (2009). Integration of structured expressive activities within a humanistic group play therapy format for preadolescents. The Journal for Specialists in Group Work, 34(3), 251-275. doi:10.1080/01933920903033487

Buser, J. K., Goodrich, K. M., Luke, M., \& Buser, T. J. (2011). A narratology of lesbian, gay, bisexual, and transgender clients' experiences addressing religious and spiritual issues in counseling. Journal of LGBT Issues in Counseling, 5(3-4), 282-303. doi:10.1080/15538605.2011.632395

Carnes-Holt, K., Meany-Walen, K., \& Felton, A. (2014). Utilizing sandtray within the discrimination model of counselor supervision. Journal of Creativity in Mental Health, 9(4), 497-510. doi:10.1080/15401383.2014.909298

Cavanaugh, K. M., \& Peters, H. C. (2019). Queer adolescents dating and sexuality: Implications for counselors, counselor educators, and supervisors. Journal of Child and Adolescent Counseling, 1-14. doi:10.1080/23727810.2018.1556986

Chang, C. Y., Ritter, K. B., \& Hays, D. G. (2005). Multicultural trends and toys in play therapy. International Journal of Play Therapy, 14(2), 69-85. doi: $10.1037 / \mathrm{h} 0088903$

Chun, K. Y., \& Singh, A. (2010). The bisexual youth of color intersecting identities development model: A contextual approach to understanding multiple marginaliza- tion experiences. Journal of Bisexuality, 10(4), 429451. doi:10.1080/15299716.2010.521059

Cochran, S. D., Björkenstam, C., \& Mays, V. M. (2017). Sexual orientation differences in functional limitations, disability, and mental health services use: Results from the 2013-2014 national health interview survey. Journal of Consulting and Clinical Psychology, 85(12), 1111-1121. doi:10.1037/ccp0000243

Dank, M., Lachman, P., Zweig, J. M., \& Yahner, J. (2013). Dating violence experiences of lesbian, gay, bisexual, and transgender youth. Journal of Youth and Adolescence, 43(5), 846-857. doi:10.1007/s10964-0139975-8

De Domenico, G. S. (1988). Sand tray world play: A comprehensive guide to the use of the sand tray in psychotherapeutic and transformational settings. Author.

Dilley, J. A., Simmons, K. W., Boysun, M. J., Pizacani, B. A., \& Stark, M. J. (2010). Demonstrating the importance and feasibility of including sexual orientation in public health surveys: Health disparities in the pacific northwest. American Journal of Public Health, 100(3), 460-467. doi:10.2105/ajph.2007.130336

Falender, C. A., \& Shafranske, E. P. (2004). Clinical supervision: A competency-based approach. American Psychological Association.

Farmer, L. B., \& Byrd, R. (2015). Genderism in the LGBTQQIA community: An interpretative phenomenological analysis. Journal of LGBT Issues in Counseling, 9(4), 288-310. doi:10.1080/15538605.2015.1103679

Fredriksen-Goldsen, K. I., Simoni, J. M., Kim, H.-J., Lehavot, K., Walters, K. L., Yang, J., ... Muraco, A. (2014). The health equity promotion model: Reconceptualization of lesbian, gay, bisexual, and transgender (LGBT) health disparities. American Journal of Orthopsychiatry, 84(6), 653-663. doi:10.1037/ort0000030

Garrett, M. (2013). Beyond play therapy: Using the sandtray as an expressive arts intervention in counselling adult clients. Asia Pacific Journal of Counselling and Psychotherapy, 5(1), 99-105. doi: $10.1080 / 21507686.2013 .864319$

Garrett, M. (2015a). Bridging the gap: using sandtray for non-secular counseling issues in secular settings. American International Journal of Contemporary Research, 5(5), 16-23. Retrieved from http://wWw.aijcrnet.com/journals/Vol -5_No_5_0ctober_2015/3.pdf

Garrett, M. (2015b). A sandtray a day keeps the doctor at play: Using sandtray for personal and professional development. Journal of Creativity in Mental Health, 10(4), 522-532. doi:10.1080/15401383.2015.1009605 
Garrett, M. (2016). Enhancing counselor supervision with sandtray interventions. Journal of Higher Education Theory and Practice, 17(5), 39-45. Retrieved from http://WWW.na-businesspress . com/JHETP/GarrettM_17_5_. pdf

Garza-Chaves, Y., Timm, N., \& Oeffinger, J. (2018). Sandtray, superheroes, and the healing journeys. Journal of Counselor Practice, 9(1), 24-38. Retrieved from https: //www . journalofcounselorpractice . com/uploads/6/8/9/4/68949193/garza _chaves_et_al_vol9_iss1.pdf

Gladding, S. T. (2010). The creative arts in counseling. American Counseling Association.

Goodrich, K. M., Buser, J. K., Luke, M., \& Buser, T. J. (2015). Spiritual and sexual identity: Exploring lesbian, gay, and bisexual clients' perspectives of counseling. Journal of Homosexuality, 63(6), 783-807. doi:10.1080/00918369.2015.1112192

Goodrich, K. M., \& Luke, M. (2009). LGBTQ responsive school counseling. Journal of LGBT Issues in Counseling, 3(2), 113-127. doi:10.1080/15538600903005284

Goodrich, K. M., \& Luke, M. (2011). The LGBTQ responsive model for supervision of group work. The Journal for Specialists in Group Work, 36(1), 22-40. doi:10.1080/01933922.2010.537739

Goodrich, K. M., \& Luke, M. (2015). Group counseling with lgbtqi persons. American Counseling Association.

Graham, M. A., Scholl, M. B., Smith-Adcock, S., \& Wittmann, E. (2014). Three creative approaches to counseling supervision. Journal of Creativity in Mental Health, 9(3), 415-426. doi:10.1080/15401383.2014.899482

Grella, C. E., Greenwell, L., Mays, V. M., \& Cochran, S. D. (2009). Influence of gender, sexual orientation, and need on treatment utilization for substance use and mental disorders: Findings from the california quality of life survey. BMC Psychiatry, 9(1). doi:10.1186/1471-244x-9-52

Guiffrida, D. A. (2015). Constructive clinical supervision in counseling and psychotherapy. Routledge.

Halpert, S. C., Reinhardt, B., \& Toohey, M. J. (2007). Affirmative clinical supervision. In K. J. Bieschke \& K. A. DeBord (Eds.), Handbook of counseling and psychotherapy with lesbian, gay, bisexual, and transgender clients (2nd ed., pp. 341-358). American Psychological Association. doi:10.1037/11482-014

Inman, A. G., \& Kreider, E. D. (2013). Multicultural competence: Psychotherapy practice and supervision. Psychotherapy, 50(3), 346-350. doi:10.1037/a0032029

Isom, E. E., Groves-Radomski, J., \& McConaha, M. M. (2015). Sandtray therapy: A familial approach to healing through imagination. Journal of
Creativity in Mental Health, 10(3), 339-350. doi:10.1080/15401383.2014.983254

Jennings, T. (2014). Sexual orientation curriculum in u.s. school counselor education programs. Journal of LGBT Issues in Counseling, 8(1), 43-73. doi:10.1080/15538605.2014.853639

Kalff, D. M. (2004). Sandplay: A psychotherapeutic approach to the psyche (the sandplay classics series). Temenos Press.

Kapitan, L., Litell, M., \& Torres, A. (2011). Creative art therapy in a community's participatory research and social transformation. Art Therapy, 28(2), 64-73. doi:10.1080/07421656.2011.578238

Kestly, T. (2010). Group sandplay in elementary schools. In A. A. Drewes \& C. E. Schaefer (Eds.), School-based play therapy (2nd ed., pp. 257-281). Wiley.

Ladany, N., Marotta, S., \& Muse-Burke, J. L. (2001). Counselor experience related to complexity of case conceptualization and supervision preference. Counselor Education and Supervision, 40(3), 203-219. doi:10.1002/j.1556-6978.2001.tb01253.x

Loue, S., \& Parkinson, J. (2015). Special ethical considerations in sandplay therapy. In S. Loue (Ed.), Ethical issues in sandplay therapy practice and research (p. 87-98). Springer.

Lowenfeld, M. (1979). The world technique. Allen \& Unwin.

Luke, M. (2008). Supervision: Models, principles, and process issues. In A. A. Drewes \& J. Mullen (Eds.), Supervision can be playful: Techniques for child and play therapist supervisors (p. 7-25). Rowman and Littlefield.

Luke, M., \& Bernard, J. M. (2006). The school counseling supervision model: An extension of the discrimination model. Counselor Education and Supervision, 45(4), 282-295. doi:10.1002/j.1556-6978.2006.tb00004.x

Luke, M., \& Goodrich, K. M. (2012). LGBTQ responsive school counseling supervision. The Clinical Supervisor, 31(1), 81-102. doi:10.1080/07325223.2012.672391

Luke, M., \& Goodrich, K. M. (2013). Investigating the LGBTQ responsive model for supervision of group work. The Journal for Specialists in Group Work, 38(2), 121-145. doi:10.1080/01933922.2013.775207

Luke, M., \& Goodrich, K. M. (2015a). Group work experts share their favorite group supervision activities: Volume 1. Association of Specialists in Group Work.

Luke, M., \& Goodrich, K. M. (2015b). Working with family, friends, and allies of lesbian, gay, bisexual, and transgender youth. Journal for Social Action in Counseling and Psychology, 7(1), 63-83. Retrieved from https://openjournals.bsu.edu/ 
jsacp/article/view/351/333

Luke, M., \& Goodrich, K. M. (2017). Assessing an LGBTQ responsive training intervention for school counselor trainees. Journal of Child and Adolescent Counseling, 3(2), 103-119. doi:10.1080/23727810.2017.1313629

Luke, M., Goodrich, K. M., \& Bond, S. (2015). Career crossroads: Supporting trans* clients in transition. In W. K. Killam, S. Degges-White, \& R. E. Michel (Eds.), Career counseling for diverse populations (pp. 87-92). Springer.

Luke, M., Goodrich, K. M., \& Scarborough, J. L. (2011). Integration of the k-12 LGBTQI student population in school counselor education curricula: The current state of affairs. Journal of LGBT Issues in Counseling, 5(2), 80-101. doi:10.1080/15538605.2011.574530

Lyles, M., \& Homeyer, L. E. (2014). The use of sandtray therapy with adoptive families. Adoption Quarterly, 18(1), 67-80. doi:10.1080/10926755.2014.945704

Markos, P. A., Coker, J. K., \& Jones, W. P. (2008). Play in supervision. Journal of Creativity in Mental Health, 2(3), 3-15. doi:10.1300/j456v02n03_02

McCurdy, K. G., \& Owen, J. J. (2008). Using sandtray in adlerian-based clinical supervision: An initial empirical analysis. Journal of Individual Psychology, 64(1), 96-112. Retrieved from https://psycnet . apa. org/record/2008-06884-008

Miller, A. C., \& Luke, M. (2018). Application of the LGBTQ responsive model for the supervision of group work to the supervision of classroom curricula. The Journal for Specialists in Group Work, 43(4), 300-325. doi:10.1080/01933922.2018.1484538

Moe, J. L., Perera-Diltz, D., \& Sepulveda, V. (2014). Beyond competence: Fostering LGBTQQI ally development through supervision. Journal of LGBT Issues in Counseling, 8(4), 389-401. doi:10.1080/15538605.2014.960129

Mullen, J. A., Luke, M., \& Drewes, A. A. (2007). Supervision can be playful, too: Play therapy techniques that enhance supervision. International Journal of Play Therapy, 16(1), 69-85. doi:10.1037/15556824.16.1.69

Nickum, J., \& Purgason, L. L. (2017). Using the sand tray to facilitate client creativity: A strengths focused approach to adolescent depression. Journal of Creativity in Mental Health, 12(3), 347-359. doi:10.1080/15401383.2016.1249814

Paone, T. R., Malott, K. M., Gao, J., \& Kinda, G. (2015). Using sandplay to address students' reactions to multicultural counselor training. International Journal of Play Therapy, 24(4), 190-204. doi:10.1037/a0039813

Pappas, S. W. (2015). A grounded theory study of expressive arts therapy used with elderly clients (Unpublished doctoral dissertation). California Institute of Integral Studies.

Perryman, K. L., Moss, R. C., \& Anderson, L. (2016). Sandtray supervision: An integrated model for play therapy supervision. International Journal of Play Therapy, 25(4), 186-196. doi:10.1037/pla0040288

Ratts, M. J., Singh, A. A., Nassar-McMillan, S., Butler, S. K., \& McCullough, J. R. (2016). Multicultural and social justice counseling competencies: Guidelines for the counseling profession. Journal of Multicultural Counseling and Development, 44(1), 28-48. doi:10.1002/jmcd.12035

Rubel, D., \& Okech, J. E. A. (2006). The supervision of group work model: Adapting the discrimination model for supervision of group workers. The Journal for Specialists in Group Work, 31(2), 113-134. doi:10.1080/01933920500493597

Soheilian, S. S., Inman, A. G., Klinger, R. S., Isenberg, D. S., \& Kulp, L. E. (2014). Multicultural supervision: supervisees' reflections on culturally competent supervision. Counselling Psychology Quarterly, 27(4), 379392. doi:10.1080/09515070.2014.961408

Stark, M. D., \& Frels, R. K. (2014). Using sandtray as a collaborative assessment tool for counselor development. Journal of Creativity in Mental Health, 9(4), 468-482. doi:10.1080/15401383.2014.897663

Stark, M. D., Frels, R. K., \& Garza, Y. (2011). The use of sandtray in solution-focused supervision. The Clinical Supervisor, 30(2), 277-290. doi:10.1080/07325223.2011.621869

Stark, M. D., Garza, Y., Bruhn, R., \& Ane, P. (2015). Student perceptions of sandtray in solution-focused supervision. Journal of Creativity in Mental Health, 10(1), 2-17. doi:10.1080/15401383.2014.917063

Stenack, R. J., \& Dye, H. A. (1982). Behavioral descriptions of counseling supervision roles. Counselor Education and Supervision, 21(3), 295-304. doi:10.1002/j.15566978.1982.tb01692.x

Sue, D. W., Arredondo, P., \& McDavis, R. J. (1992). Multicultural counseling competencies and standards: A call to the profession. Journal of Counseling $\mathcal{E}$ Development, 70(4), 477-486. doi:10.1002/j.15566676.1992.tb01642.x

Swank, J. M., \& Lenes, E. A. (2013). An exploratory inquiry of sandtray group experiences with adolescent females in an alternative school. The Journal for Specialists in Group Work, 38(4), 330-348. doi:10.1080/01933922.2013.835013

Thorne, N., Witcomb, G. L., Nieder, T., Nixon, E., Yip, A., \& Arcelus, J. (2018). A comparison of mental health symptomatology and levels of social support in young treatment seeking transgender individuals who identify as binary and non- 
binary. International Journal of Transgenderism, 110. doi:10.1080/15532739.2018.1452660

Troutman, O., \& Packer-Williams, C. (2014). Moving beyond CACREP standards: Training counselors to work competently with LGBT clients. The Journal for Counselor Preparation and Supervision. doi: $10.7729 / 61.1088$

Yalom, I. D., \& Leszcz, M. (2005). Theory and practice of group psychotherapy (5th ed.). Basic Books.

Zeglin, R. J., Van Dam, D., \& Hergenrather, K. C. (2018). An introduction to proposed human sexuality counseling competencies. International Journal for the Advancement of Counselling, 40(2), 105-121. doi:10.1007/s10447-017-9314-y 